\title{
EKSTRAK TANNIN DAUN BUAH HITAM (Haplolobus sp) SEBAGAI INHIBITOR ALAMI KOROSI BESI DALAM LARUTAN ASAM
}

\section{TANNIN EXTRACT OF BLACK FRUIT LEAVES (Haplolobus sp) AS NATURAL CORROSION INHIBITOR OF IRON IN ACID SOLUTION}

\author{
Evelina Somar dan Lulu Amalia Rahman \\ Jurusan Kimia Fakultas Matematika dan Ilmu Pengetahuan Alam Universitas Papua \\ E.mail: e.somar@unipaac.id
}

\begin{abstract}
ABSTRAK
Ekstrak daun Haplolobus $s p$ diperoleh dari sokhetasi daun yang telah dikeringkan dan diperkecil ukurannya, dengan pelarut aseton $80 \%$. Ekstrak yang diperoleh kemudian diuapkan dan ditentukan kadar taninnya dengan metode permanganometri. Pengukuran laju korosi logam besi dilakukan dengan metode pengurangan massa. Medium korosi yang digunakan adalah $\mathrm{H}_{2} \mathrm{SO}_{4}$, $\mathrm{H}_{3} \mathrm{PO}_{4}, \mathrm{CH}_{3} \mathrm{COOH}, \mathrm{HNO}_{3}$, dan $\mathrm{HCl}$ masing-masing dengan konsenttrasi 1 molar. Lama perendaman sepuluh hari. Potensi tanin daun buah hitam sebagai inhibitor alami dalam laju reaksi korosi logam besi dilakukan dengan melapisi logam besi ukuran $2 \mathrm{~cm} \times 2 \mathrm{~cm} \times 0,3 \mathrm{~cm}$, direndam 10 hari dalam medium korosi dan diukur laju korosinya. Cara yang sama diulangi dengan menggunakan cat antikarat. Dari hasil penelitian di peroleh kadar tanin dalam daun Buah Hitam (Haplolobus sp) sebesar 42,16\%. Laju korosi logam besi tanpa pelapisan tanin tertinggi pada asam nitrat 13829.40 mpy dan terendah pada asam asetat 1646,36 mpy. Laju korosi logam besi yang dilapisi tanin tertinggi pada asam nitrat $13061.10 \mathrm{mpy}$, dan terendah pada asam asetat 1536,60 mpy. Laju korosi logam besi yang dilapisi cat antikorosi tertinggi pada asam nitrat 7573,24 mpy dan terendah pada asam asetat 1536,60 mpy. Efisiensi penghambatan tanin dan cat terhadap laju korosi logam besi dalam medium asam sulfat $1 \mathrm{M}$ sebesar 25,64 \% dan 41,03\%, dalam medium asam fosfat sebesar $12,50 \%$ dan $16,67 \%$, dalam medium asam asetat sebesar 6,67 dan $6,67 \%$, Dalam medium asam nitrat sebesar 5,56 dan 45,24\%, dalam medium asam klorida 5,56 dan 5,56\%.
\end{abstract}

Kata kunci: tanin, inhibitor alami, korosi besi

\section{Pendahuluan}

Korosi pada logam merupakan peristiwa alami yang tidak dapat dihindari, namun dapat dihambat dan dikendalikan. Salah satu cara mengendalikan korosi adalah dengan melapisi permukaan logam menggunakan cat antikarat. Namun cat antikarat mengandung bahan kimia berbahaya bagi lingkungan dan kesehatan manusia. sehingga dibutuhkan alternative lain yaitu zat antikorosi yang lebih aman bagi kesehatan, murah dan ramah lingkungan seperti antikrosi alami dari ekstrak tumbuhan.
Ekstrak tumbuhan yang mengandung senyawa polifenol seperti tanin dapat digunakan sebagai zat antikorosi pada baja AISI dengan efisiensi penghambatan 50\% (Matamala, 2000). Myricetin dan rutin dalam ekstrak daun Crytostegia grandiflora dapat menghambat laju korosi baja dalam larutam $\mathrm{H}_{2} \mathrm{SO}_{4} 1 \mathrm{M}$ (Prabakaran et al,2016). Buah hitam (Haplolobus sp) merupakan salah satu tumbuhan endemik Papua dan diketahui daun buah hitam mengandung tanin dengan kadar berkisar antara 8,34 - 37,26\% (Somar ,2014), sehingga berpotensi sebagai zat antikorosi, 
namun belum diketahui berapa besar kemampuannya dalam menghambat laju korosi besi dalam larutan asam.

Penelitian ini bertujuan untuk mengekstrak dan menentukan kadar tanin dalam daun buah hitam, dan menentukan efisiensi penghambatannya terhadap laju korosi besi dalam beberapa larutan asam

\section{Metode Penelitian}

\section{Pembuatan Ekstrak}

Sampel daun buah hitam dikeringkan dalam oven pada suhu $40^{\circ} \mathrm{C}$ selama 24 jam, setelah kering diperkecil ukurannya dan disokletasi menggunakan pelaarut aseton $80 \%$ selama 8 jam. Pelarut diuapkan menggunakan rotary evaporator hingga diperleh ekstrak kental.

\section{Uji Tanin}

Sebanyak $3 \mathrm{~mL}$ ekstrak ditambahkan $5 \mathrm{~mL}$ aquadest, dipanaskan Selma 30 menit lalu didinginkan. Tambahkan 5 tetes $\mathrm{NaCl}$ $10 \%$ dan disaring, kemudian dibagi menjadi 2. Filtrat A sebagai blangko dan filtrat $B$ ditambahkan 5 tetes $\mathrm{FeCl}_{3} \quad 1 \%$. Jika terbentuk warna hijau kehitaman atau biru kehitaman maka positif mengandung tanin.

\section{Penentuan Kadar Tanin}

Penentuan kadar tanin menggunakan metode permanganometri. 1,5 gram ekstrak dimasukkan kedalam gelas piala $100 \mathrm{~mL}$, tambahkan auadest $5 \mathrm{~mL}$, panaskan pada suhu $40-60^{\circ} \mathrm{C}$ selama 30 menit. Setelah dingin disaring kedaam abu ukur $250 \mathrm{~mL}$ tambahkan auadest sampai tanda tera. Ambil $25 \mathrm{~mL}$ larutan tersebut masukkan kedaam erenmeyer. Tambahakan $20 \mathrm{~mL}$ larutan indigokarmin kemudian titrasi dengan larutan
$\mathrm{KMnO}_{4}$ 0,1 $\mathrm{N}$ sampai larutan berubah dari biru menjadi hijau, titrasi dianjutkan sampai larutan berwarna kuning emas. Misalkan volume titran A mL. Penetapan blanko dilakukan dengan titrasi campuran larutan 20 $\mathrm{mL}$ larutan indigokarmin dan $25 \mathrm{~mL}$ aquadest dengan $\mathrm{KMnO}_{4} \quad 0,1 \quad \mathrm{~N}$. misalkan diperoleh volume titran $\mathrm{B} \mathrm{mL}$. Kadar tanin dihitung menggunakan rumus:

$$
\% \text { Tanin }=\frac{10 \frac{(A-B) N}{0,1 \times 0,00416}}{\text { Berat Smape }} \times 100 \%
$$

Dengan: $\mathrm{A}=$ volume titrasi ekstrak $(\mathrm{mL})$

$\mathrm{B}=$ volume titrasi blanko $(\mathrm{mL})$

$\mathrm{N}=$ Normaitas KMnO4 0,1 N

$10=$ faktor pengenceran

$1 \mathrm{~mL} \mathrm{KMnO} 4 \approx 0,0416 \mathrm{~g}$ tanin

\section{Penentuan Laju Korosi}

Sampel besi dengan ukuran $2 \mathrm{~cm} \times 2$ $\mathrm{cm} \times 0,3 \mathrm{~cm}$ yang telah dibersihkan dan ditimbang berat awal, direndam dalam larutan $\mathrm{H}_{2} \mathrm{SO}_{4} 1 \mathrm{M}, \mathrm{HNO}_{3} 1 \mathrm{M}, \mathrm{H}_{3} \mathrm{PO}_{4} 1 \mathrm{M}$, $\mathrm{HCl} 1 \mathrm{M}$, dan $\mathrm{CH}_{3} \mathrm{CO}_{2} \mathrm{H} 1 \mathrm{M}$ selama 10 hari. Kemudian dibersihkan dan dikeringkan dalam oven, pada suhu $40^{\circ} \mathrm{C}$ selama 5 menit, alu didinginkan dan ditimbang berat akhir. Dilakukan triplet. Langkah yang sama diulangi pada sampel yang telah dilapisi ekstrak tanin daun buah hitam dan cat antikarat.. Laju korosi dihitung mengunakan rumus:

$$
v_{k}(m p y)=\frac{K \times M}{A x t \times d}
$$

Dengan : $v_{k}=$ laju korosi

$$
\begin{aligned}
\mathrm{K}= & \text { konstanta } 3,45 \times 10^{6} \\
\mathrm{M}=\text { pengurangan berat akibat } & \text { korosi }(\mathrm{g}) \\
\mathrm{t}= & \text { lama waktu pengujian (sekon) } \\
\mathrm{d}= & \text { berat jenis logam }\left(\mathrm{g} / \mathrm{mm}^{3}\right) \\
\mathrm{A}= & \text { Luas permukaan logam }\left(\mathrm{mm}^{3}\right)
\end{aligned}
$$


Efisiensi inhibisi dihitung menggunakan rumus:

$$
\text { Efisiensi Inhibisi }=\frac{v_{k_{o}}-v_{k_{i}}}{v_{k_{o}}}
$$

Dengan

$$
\begin{aligned}
& v_{k_{o}}=\text { laju korosi tanpa pelapisan } \\
& v_{k_{i}}=\text { laju korosi dengan pelapisan }
\end{aligned}
$$

\section{Hasil dan Pembahasan}

Ekstrak daun buah hitam menunjukkan uji positif mengandung tanin dengan terbentuknya warna hijau kehitaman pekat . Hasil penelitian di peroleh kadar tanin dalam daun Buah Hitam (Haplolobus $s p)$ sebesar $42,16 \%$. Larutan asam merupakan medium korosi yang baik, karena sifat oksidator asam akan mengksidasi logam $\mathrm{Fe}$ menjadi ion $\mathrm{Fe}^{2+}$ yang tidak stabil, yang dapat bereaksi dengan ion hidroksil hasil disosiasi air, dan bereaksi kembali dengan iion $\mathrm{Fe} 2+$ menghasikan endapan Fe3O4 yang berwarna kuning kemerahan. (Widharto, 2004)

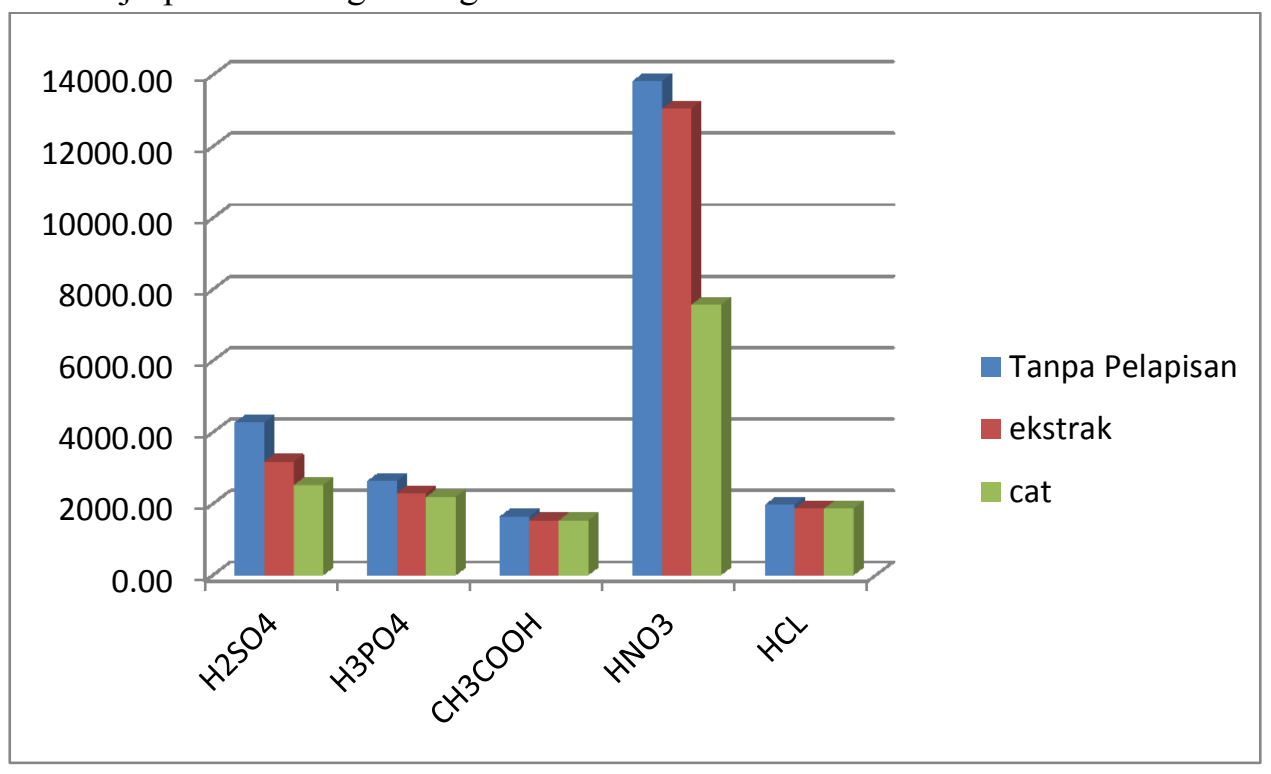

Gambar1.. Laju korosi besi dalam larutan asam 1M

Laju korosi besi ditampilkan pada gambar 1. Laju korosi besi tanpa pelapisan tanin tertinggi pada asam nitrat 13829.40 mpy dan terendah pada asam asetat 1646,36 mpy. Laju korosi logam besi yang dilapisi tanin tertinggi pada asam nitrat 13061.10 mpy, dan terendah pada asam asetat 1536,60 mpy. Laju korosi logam besi yang dilapisi cat antikorosi tertinggi pada asam nitrat 7573,24 mpy dan terendah pada asam asetat 1536,60 mpy. 


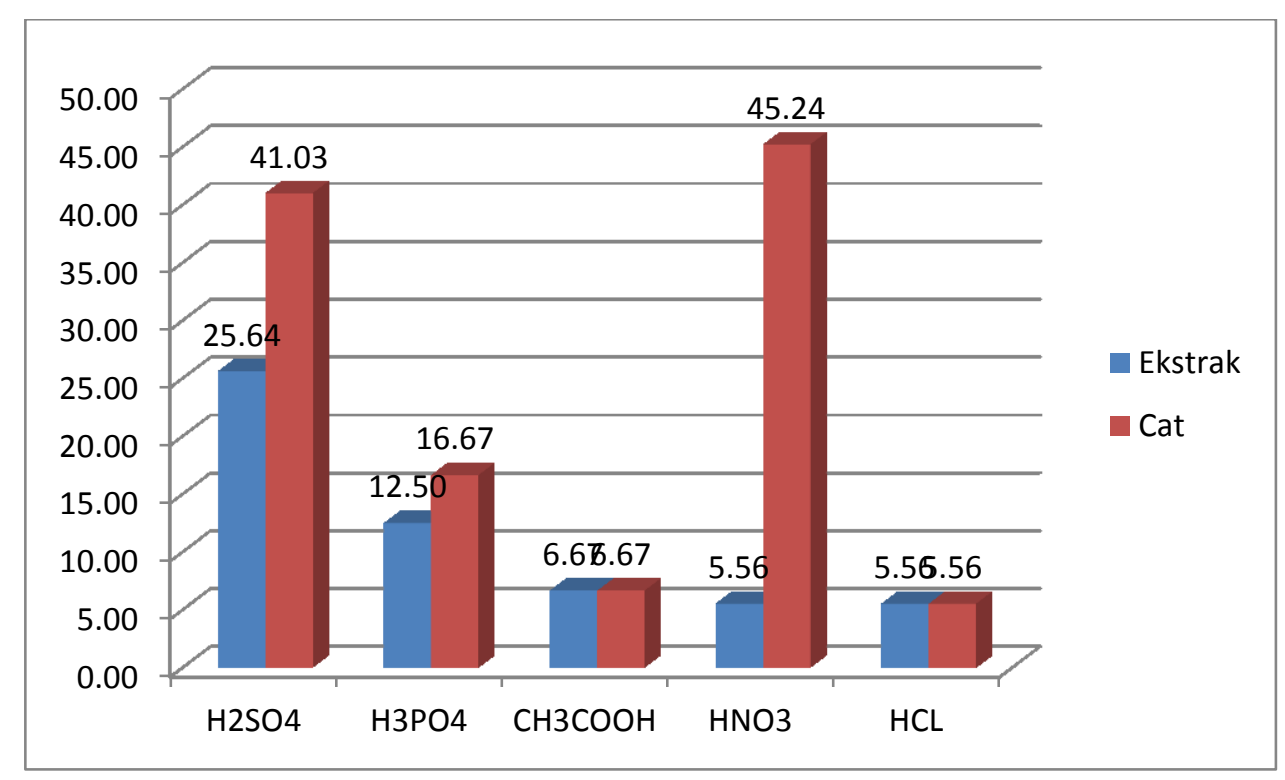

Gambar 2. Efisiensi penghambatan laju korosi besi dalam larutan asam $1 \mathrm{M}$

Efisiensi penghambatan tanin dan cat terhadap laju korosi besi dtunjukkan pada gambar 2. Efisiensi penghambatan tanin dan cat terhadap laju korosi logam besi dalam medium asam sulfat $1 \mathrm{M}$ sebesar $25,64 \%$ dan $41,03 \%$, dalam medium asam fosfat sebesar $12,50 \%$ dan $16,67 \%$, dalam medium asam asetat sebesar 6,67 dan 6,67\%, Dalam medium asam nitrat sebesar 5,56 dan $45,24 \%$, dalam medium asam klorida 5,56 dan $5,56 \%$.

Tanin dapat bersifat sebagai inhibitor korosi besi karena gugus $-\mathrm{OH}$ pada cincin aromatik tanin dapat membentuk kompleks chelat dengan besi, berupa lapisan tipis pada permukaan besi sehingga menghalangi interaksi antara asam dengan permukaan besi. Kompleks tanin-besi dapat terbentuk pada tanin terkondensasi dan tanin terhidrolisis (Yahya et al, 2008) melaporkan bahwa pembentukan tanat besi terbentuk pada tanin terkndensasi dan tanin terhidroisis. ketika ion $\mathrm{Fe}^{3+}$ bereaksi dengan gugus $-\mathrm{OH}$ dalam orthoposisi dalam larutan air aerasi membentuk kompleks yang sangat tidak larut dan bewarna biru kehitaman (Gust and Suwalski, 1994).

\section{Kesimpulan}

Ekstrak daun buah hitam (Haplolobus sp) dengan kadar tanin sebesar $42,16 \%$ lebih berpotensi menghambat laju korosi logam besi dalam larutan asam sulfat $1 \mathrm{M}$ dan tidak efisien menghambat laju korosi besi dalam larutan asam nitrat $1 \mathrm{M}$.. 


\section{Daftar Pustaka}

J. Gust and J. Suwalski. 1994. Use Of MossbauerSpectroscopy to Study Reaction Products Of Pollyphenols and Iron Compounds. Corrosion, Vol..50. No. 5 pp. $355-365$

Matamala G., Smeltzer W., Droguett G. 2000. Comparison of steel anticorrosive protection formulated with natural tannins extracted from acacia and from pine bark. Corrosion Science Volume 42, Issue 8, Pages 1351-1362

Prabakaran Mayakrishnan., Kim SeungHyun., Hemapriya Venkatesan., Chung IllMin. 2016. Evaluation of polyphenol composition and anti-corrosion properties of Cryptostegia grandiflora plant extract on mild steel in acidic medium. Abstract.
Journal of Industrial and Engineering Chemistry. http:// www sciencedirect. com/science /article /pii /S1226 086X16300090.

Somar E. 2014, Pengaruh Faktor Abiotik Terhadap Kadar Tanin daun Buah Hitam (Haplolobus cf.monticola Husson) Asal Kabupaten Teluk wondama. Tesis, Program Pascasarjana Unipa Manokwari

S. Yahya, A.M Shah,A.A, Rahim, N.H.A. Aziiz, and R. Roslan. 2008. Phase Transformation of Rust in The Presence of Various Tannins. Journal of Physical Science, Vol. 19, No. 1, pp. 31-41

Widharto, S. 2014. Karat dan Pencegahannya. Edisi ketiga. PT Pradnya Paramita. Jakarta 